\title{
Learning and academic success in engineering courses: Comparing 1st year students according to gender
}

\author{
Vasconcelos, Rosa M. \\ President of Pedagogical Council of the School of \\ Engineering of University of Minho \\ Guimarães, Portugal \\ rosa@det.uminho.pt
}

\author{
Almeida, Leandro S. \\ Education Institute of University of Minho \\ Braga, Portugal \\ leandro@,ie.uminho.pt
}

\begin{abstract}
This work in-progress research to practice paper analyzes the learning achievements of first-year engineering students, in order to observe if there are eventual gender differences. Studies suggest that women have higher enrollment rates and achievements in Higher Education. Women also dedicate more time studying and are more committed attaining their degree than men. Although the percentage of female students' application in Science, Technology, Engineering and Mathematics (STEM) courses increased in the last years, there is still a greater proportion of women choosing higher education in social sciences and humanities areas. A sample of $7231 \mathrm{st}$ year engineering students (66.8\% male) was analyzed according to their academic background, their social origin and their habits of study. The results do not differentiate the Engineering Students according to their gender in socio-cultural variables of origin, however they significantly differentiate the two groups of students in their habits of study. Female students show greater organization of their time and activities of study, being also more thoughtful and self-regulated learners. At the same time, at the end of the first semester, they present a higher rate of successful curricular units and higher average grades. Some implications are highlighted for the teaching-learning process in engineering courses.
\end{abstract}

Keywords - Higher Education; academic expectations; engineering students; learning outcomes; academic success; gender.

\section{INTRODUCTION}

The expansion of Higher Education (HE) in Portugal, during the last three decades, through the creation of new institutions and new courses resulted in a more widespread access of the population to this level of education. This expansion seeks to respond to the European community's goals of increasing the number of graduates among the
Portuguese adult population who enter the labor market (European target of $40 \%$ of young adults with HE degree in 2020) and to the effort for greater democratization and social justice in the access to HE [1]. This expansion has two main aspects that characterize the access to $\mathrm{HE}$ in Portugal: a greater diversity of students and the need to implement a numerus clausus system to the access.

The democratization of Higher Education access was logically reflected in an exponential increase of the number of students. In the 1970's there were 60,000 students in Higher Education Institutions (HEI), raising to 400 thousand in the academic year of 2002/3 (exceeding almost $650 \%$ ). This increase was achieved through greater heterogeneity of the student population in terms of their sociocultural origin, academic skills, motivations and vocational projects [2]. By putting an end to "Elite Universities", Higher Education Institutions (HEI) started receiving students from rural areas, less favored social groups or ethnic minority groups, who tend to be less familiar with the academic culture and its challenges, as well as older students, who had already built family and started a professional activity[3].

The transition to HE is, therefore, particularly challenging for several subgroups of students, for example those who will need to reconcile professional activity and family with study activities, or even younger students, because some of them leave their parents' houses for the first time and have to build a new social and emotional support network [4,5]. At the same time, teaching methodologies changed and students are faced with less educational practices supported by school handbooks, with less close and less frequent feedback from teachers about their learning [6,7]. This learning and performance difficulties might be more frequent among male students, who tend to enter higher education with less studying competencies and lower average grades, although these variables are predictors of 
academic performance of the first year of the university [8, 9].

In fact, the research points out that female students present more self-regulated behaviors, for example in classes participation, time management study, they are more responsible on group-work, as well as more critical in administration and logistics institutional teaching-learning conditions $[10,11]$. Female students present deep learning approaches, defined by understanding rather than memorization approach $[12,13]$.

Another aspect to be considered is that, given the greater demand for HE, it was necessary to implement a numerus clausus system in the access to the vacancies of each institution and course defined by the Ministry of Science and Technology and Higher Education (MSTHE). Currently, the access to University is determined by a national competition in which entry is made according to an application mark, that weighs the student's ratings in High School and in national exams according to the specification of the courses. In Engineering courses, Mathematics and Chemical Physics are compulsory disciplines. As a consequence, students who are not placed in their first option courses end up being placed in second options, occupying the vacancies of students with lower average grades, generating a wave of displacement and dissatisfaction [14]. According to MSTH data, in recent years, about half of the students are not placed in their first choice courses, nor in the institution that they would prefer, with greater selection of candidates in the areas of health and engineering. In Portugal, this selection process of students is marked by the cultural origin of students, registering a higher percentage of students coming from disadvantaged social strata in courses of Humanities and Social Sciences, or attending courses at Polytechnic Institutions $[15,16]$.

Regarding courses in the fields of Science, Technology, Engineering and Mathematics (STEM), it is important to analyze the variable "gender" in this expansion. Even though the number of women in this group of courses has increased, certain social and career stereotypes are maintained, since they are clearly the majority in social sciences and humanities courses [2].

In this article, we want to analyze some of engineering students gender characteristics, as well as vocational options and academic performance. Some research indicates that women have higher enrollment rates and achievements and that they dedicate more time studying and are more involved in their degree than men, so it is possible to anticipate a better academic achievement.

\section{METHOD}

Participants

The sample is composed by 723 first year students from all engineering courses of one public university. Most of the participants are male $(66,8 \%)$
Instrument and Procedure

At the time of their enrollment at the university, students answered a social and academic characterization questionnaire, integrating three main topics: (i) Family socioeconomic origin, (ii) vocational options, in particular whether or not they were going to attend a course in a first choice institution, and (iii) the past level of basic and secondary schooling, including three questions about their study competencies (organization of their time and activities of study, surface versus deep learning approach and self-regulated learning). The students have been informed of the study's objectives, they were guaranteed the confidentiality of the information and they gave their informed written consent, also authorizing access to their academic classifications at the end of the first semester. The statistical treatment of the results resort to the package SPSS/IBM version 23.0.

\section{RESULTS}

In table 1, we describe students' socio-cultural background, previous academic experience and vocational options. According to some of the data collected, we indicate the following parameters:

- family socioeconomic status (SES), combining professional activity and degree of academic qualifications in four classes: low, medium low, medium high and high;

- if the student will have to leave the parents' house to attend HE (LH);

- $\quad$ if he/she is attending a course and a university of 1st option,

- the average grades of enrollment in HE (classification from 0 to 200)

- academic performance at the end of the first semester (average of grades on a scale of 0 to 20,

- number of curricular units (CU) attended with success, this means with a minimum classification of 10).

This description is made by gender, with only one third of the students being female $(n=240,33.2 \%)$. The differences in the effective ratio and the means are evaluated in terms of statistical significance using the chisquare test and t-test according to the metrics of the variables under analysis.

Results suggest a balance of the socioeconomic origins of students of both genders, without a significant statistic difference in their distribution $(\mathrm{X} 2=3.039$, df $=3, \mathrm{p}=$ .386).

In Portugal, the majority of the students that are enrolled in HEI come from an intermediary social stratum, with about $20 \%$ of the students with low socioeconomic origins.

It is interesting to note a greater proportion of female students who leave their parents' houses to attend higher education in engineering courses (X2 18.159, df $=1$, $p$ 000 ), suggesting a higher female investment in higher 
education and willingness to move, or a greater sense of autonomy to face the challenges of transition and adapting to $\mathrm{HE}$, without close family support.

Table 1- Descriptive of students by gender

\begin{tabular}{|l|l|l|}
\hline Variables & Male $(\mathrm{N}=489,66.8 \%)$ & Female $(\mathrm{N}=240,33.2 \%)$ \\
\hline SES: & & \\
- Low & $\mathrm{N}=83(17.2 \%)$ & $\mathrm{N}=54(22.5 \%)$ \\
- Medium low & $\mathrm{N}=164(34.0 \%)$ & $\mathrm{N}=74(30.8 \%)$ \\
- Medium high & $\mathrm{N}=182(37.7 \%)$ & $\mathrm{N}=87(36.3 \%)$ \\
- High & $\mathrm{N}=54(11.2 \%)$ & $\mathrm{N}=25(10.4 \%)$ \\
\hline LH (yes) & $\mathrm{N}=153(31.7 \%)$ & $\mathrm{N}=116(48.3 \%)$ \\
\hline 1st option & $\mathrm{N}=250(51.8 \%)$ & $\mathrm{N}=126(52.5 \%)$ \\
\hline 1st option university & $\mathrm{N}=348(72.0 \%)$ & $\mathrm{N}=160(66.7 \%)$ \\
\hline Study time and & $\mathrm{M}=4.05, \mathrm{SD}=0.95$ & $\mathrm{M}=4.66, \mathrm{SD}=0.64$ \\
activities organization & & \\
\hline Deep learning approach & $\mathrm{M}=3.85, \mathrm{SD}=1.03$ & $\mathrm{M}=4.38, \mathrm{SD}=.61$ \\
\hline Self-regulated learning & $\mathrm{M}=2.51, \mathrm{SD}=1.45$ & $\mathrm{M}=3.25, \mathrm{SD}=1.09$ \\
\hline Entrance average grade & $\mathrm{M}=152.46, \mathrm{SD}=17.98$ & $\mathrm{M}=158.89, \mathrm{SD}=17.31$ \\
\hline 1st semester mean & $\mathrm{M}=12.56, \mathrm{SD}=3.24$ & $\mathrm{M}=13.82, \mathrm{SD}=2.19$ \\
\hline Nr. of CU approved & $\mathrm{M}=4.35, \mathrm{SD}=1.55$ & $\mathrm{M}=5.16, \mathrm{SD}=.18$ \\
\hline
\end{tabular}

Taking the vocational options of the students as a result of the policy of numerus clauses, we observe a very close percentage of students of both genders who attend a course of their $1^{\text {st }}$ option, with a slight increase in the percentage of male students attending a university on their $1^{\text {st }}$ option (even if this difference does not assume statistical significance: $\mathrm{X} 2=2,337, \mathrm{df}=1, \mathrm{p}=127$ ).

According to the percentage values obtained, regarding both genders, the percentage of students who reported being placed in a 1st option institution is higher than in a 1 st option course, suggesting a greater attractiveness for the university and that many of these students will try to move to the course of their $1^{\text {st }}$ choice at the end of the first year, particularly if the course they are attending does not correspond to their expectations.

In terms of study habits in High School, female students present a more positive self-assessment, in terms of behaviors and strategies, who seek a more efficient learning. Female students present better organization of their time and activities of study $(\mathrm{t}=6.078 ., \mathrm{p}<-001)$, a deeper learning approach $(\mathrm{t}=10.113, \mathrm{p}<.001)$, and greater self-regulation learning $(\mathrm{t}=7459, \mathrm{p}<.001)$.

Finally, the results of the survey indicate that female students do not only enter higher education with a higher average application grade $(\mathrm{t}=-4.582, \mathrm{p}<.001)$, but that they also obtain a higher average grade during the first semester, and attend successfully a higher number of curricular units $(\mathrm{t}=7.011, \mathrm{p}<.001)$.

\section{FINAL REMARKS}

Due to the expansion of Higher Education in Portugal, during the last few decades, the majority of male students remain in engineering courses (only one-third of students are female). This situation will be surely different depending on the engineering area of the attended course, but this difference, in favor of male students, is clearer in computer courses. Regarding students who leave their parents' houses to attend higher education, there is a greater proportion of female students in this situation. This aspect may show that there is a greater investment in higher academic training as a way of achieving greater emancipation. Since female students value more the quality of the interpersonal relations, it is important to take care of the academic context that welcomes them, especially those who need to create a new network of friends and social support. Regarding students' vocational choices, we notice that the University has greater influence on students than the course, specially what concerns male students. This aspect requires more attention from the course directors and $1^{\text {st }}$ year professors, since students need to be motivated for the course that they are attending and explore alternatives for their professional careers. Special attention must be given to male students, in order to increase their academic competencies to promote engagement, self-regulated learning and better achievements. As in Portugal a large percentage of students are not attending a first option degree, it is important to invite people from companies to develop Seminars and workshops in order to promote motivation and career developments in the engineering field.

\section{ACKNOWLEDGMENT}

This work is financed by FEDER funds through the Competitivity Factors Operational Programme COMPETE and by national funds through FCT Foundation for Science and Technology within the scope of the project POCI-01-0145-FEDER-007136 and FCOMP- 01-0124-FEDER-022674

\section{REFERENCES}

[1] Dias, D., Marinho-Araújo, C., Almeida, L., \& Amaral, A. (2011). The democratisation of access and success in higher education: The case of Portugal and Brazil. Higher Education Management and Policy, 23(1), 23-42.

[2] Casanova, J. R., \& Almeida, L. S. (2916). Diversidade de públicos no ensino superior: Antecipando riscos na qualidade da adaptação e do sucesso académico em estudantes do $1^{\mathrm{o}}$ ano. Psicologia, Educação e Cultura, XX(1)), 27-45

[3] Almeida, LS, Guisande, MA, Soares, AP \& Saavedra, L. (2006). Access and success in Higher Education in Portugal: Gender issues, socio-cultural background and students' academic trajectory. Psychology: Reflection

[4] Benson, J. E. (2007). Make new friends but keep the old: peers and the transition to college. Interpersonal Relations Across the Life Course Advances in Life Course Research, 12, 309-334.

[5] Credé, M., \& Niehorster, S. (2012). Adjustment to college as measured by the Student Adaptation to College Questionnaire: A quantitative review of its structure and relationships with correlates and consequences. Educational Psychology Review, 24, 133-165..

[6] Bariani, I. C. D., \& Pavani, R. (2008). Sala de aula na universidade: espaço de relações interpessoais e participação acadêmica. Estudos de Psicologia, 25(1), 67-75.

[7] Hagenauer, G., \& Volet, S. E. (2014). Teacher-student relationship at university: an important yet under-researched field. Oxford Review of Education, 40(3), 370-388. 
[8] Dennis, J. M., Phinney, J. S., \& Chuateco, L. I. (2005). The role of motivation, parental support, and peer support in the academic success of ethnic minority first-generation college students. Journal of College Student Development, 46, 223-236. doi:10.1353/csd.2005.0023N.

[9] Robbins, S. B., Allen, J., Casillas, A., Peterson, C. H., \& Le, H. (2006). Unraveling the differential effects of motivational and skills, social, and self-management measures from traditional predictors of college outcomes. Journal of Educational Psychology, 98, 598-616. doi:10.1037/0022-0663.98.3.598

[10] Grebennikov, L., \& Skaine, I. (2009). Gender and higher education experience: a case study. Higher Education Research \& Development, 28(1), 71-84. DOI: 10.1080/07294360802444370

[11] Zimmerman, B.J. (2001). Theories of self-regulated learning and academic achievement: An overview and analysis. In B.J. Zimmerman \& D.H. Schunk (Eds.), Self-regulated learning and academic achievement: Theoretical perspectives (2nd ed., pp. 137). Mahwah, NJ: Erlbaum

[12] Entwistle, N. J. (1988). Motivational factors in students' approaches to learning. In R. R. Schmedk (Ed.), Learning strategies and learning styles (pp. 21-51). New York: Plenum Press.

[13] Diniz, A. M., Alfonso, S., Araújo, M. A., Deaño, M., Costa, A. R. Conde, A., \& Almeida, L. S. (2018). Gender differences in firstyear college students' academic expectations. Studies in Higher Education, 43(4), 689-701, DOI: 10.1080/03075079.2016.1196350

[14] Fonseca, M., Dias, D., Sá, C., \& Amaral, A. (2013). Waves of (dis)satisfaction: Effects of the numerus clausus system in Portugal. European Journal of Education, 49(1), 144-158.

[15] Lopes, J. T. (2016). A universidade e os seus estudantes. Um olhar de dentro. Revista Lusófona de Estudos Culturais, 3(2,81-90

[16] Machado, F. L., Costa, A. F., Mauritti, R., Martins, R. C. Casanova, J. L., \& Almeida, J. F. (2003). Classes sociais e estudantes universitários: Origens, oportunidades e orientações. Revista Crítica de Ciências Sociais, 66, 45-80. 